\title{
Application of Neon Ion Implantation to Generate Intermediate Energy Levels in the Band Gap of Boron-Doped Silicon as a Material for Photovoltaic Cells
}

\author{
Paweł Węgierek * (D) and Justyna Pastuszak (D)
}

Citation: Węgierek, P.; Pastuszak, J. Application of Neon Ion Implantation to Generate Intermediate Energy Levels in the Band Gap of Boron-Doped Silicon as a Material for Photovoltaic Cells. Materials 2021, 14, 6950. https://doi.org/10.3390/ma14226950

Academic Editors: Marek Lipiński and Johann Bouclé

Received: 14 September 2021

Accepted: 15 November 2021

Published: 17 November 2021

Publisher's Note: MDPI stays neutral with regard to jurisdictional claims in published maps and institutional affiliations.

Copyright: (c) 2021 by the authors. Licensee MDPI, Basel, Switzerland. This article is an open access article distributed under the terms and conditions of the Creative Commons Attribution (CC BY) license (https:// creativecommons.org/licenses/by/ $4.0 /)$.
Faculty of Electrical Engineering and Computer Science, Lublin University of Technology, Nadbystrzycka 38 A, 20-618 Lublin, Poland; j.pastuszak@pollub.pl

* Correspondence: p.wegierek@pollub.pl; Tel.: +48-81-538-43-47

Abstract: The aim of the work is to present the possibility of generating intermediate levels in the band gap of p-type silicon doped with boron by using neon ion implantation in the aspect of improving the efficiency of photovoltaic cells made on its basis. The work contains an analysis of the influence of the dose of neon ions on the activation energy value of additional energy levels. The article presents the results of measurements of the capacitance and conductance of silicon samples with a resistivity of $\rho=0.4 \Omega \mathrm{cm}$ doped with boron, the structure of which was modified in the implantation process with $\mathrm{Ne}^{+}$ions with the energy $E=100 \mathrm{keV}$ and three different doses of $D=4.0 \times 10^{13} \mathrm{~cm}^{-2}, 2.2 \times 10^{14} \mathrm{~cm}^{-2}$ and $4.0 \times 10^{14} \mathrm{~cm}^{-2}$, respectively. Activation energies were determined on the basis of Arrhenius curves $\ln \left(\mathrm{e}^{\mathrm{t}}\left(T_{\mathrm{p}}\right) / T_{\mathrm{p}}{ }^{2}\right)=\mathrm{f}\left(1 / \mathrm{k} T_{\mathrm{p}}\right)$, where $T_{\mathrm{p}}$ is in the range from $200 \mathrm{~K}$ to $373 \mathrm{~K}$ and represents the sample temperature during the measurements, which were carried out for the frequencies $f_{\mathrm{p}}$ in the range from $1 \mathrm{kHz}$ to $10 \mathrm{MHz}$. In the tested samples, additional energy levels were identified and their position in the semiconductor band gap was determined by estimating the activation energy value. The conducted analysis showed that by introducing appropriate defects in the silicon crystal lattice as a result of neon ion implantation with a specific dose and energy, it is possible to generate additional energy levels $\Delta E=0.46 \mathrm{eV}$ in the semiconductor band gap, the presence of which directly affects the efficiency of photovoltaic cells made on the basis of such a modified material.

Keywords: intermediate band solar cells; ion implantation; photovoltaic cells efficiency; defects; electrical parameters of silicon; activation energy

\section{Introduction}

\subsection{Background and Motivation}

The dynamic development of the renewable energy sector, based primarily on photovoltaics [1-3] causes the need for research and development in a wide range of issues related to the solar energy conversion technology itself, production processes and operation, as well as sustainable development [4-6]. Particularly important is research aimed at increasing the efficiency of PV cells, which directly affects the profitability of their production manufacturing and application [3].

Currently, the mainstream development of photovoltaic technology concerns cells based on monocrystalline silicon, which constitute about $80 \%$ of all cells produced, while nearly $70 \%$ are based on p-type silicon, most often obtained by boron doping $[7,8]$.

Analyzing the current state of the art in the field of research on methods of increasing the efficiency of crystalline silicon photovoltaic cells, a multi-threaded approach is required, focused on reducing internal losses that affect the efficiency of the cell. The total internal losses in a photovoltaic cell can be divided into electrical, optical and quantum losses [9]. Activities aimed at increasing the efficiency of electricity generation in solar cells are undertaken in all three areas, but the greatest development potential concerns methods of 
reducing optical and quantum losses, which are closely related to the internal structure and properties of the cell material. The key is the energy gap $E_{\mathrm{g}}$, which determines the energy a photon incident on the cell surface must have in order to be absorbed and participate in the photovoltaic conversion process. As it is known, for silicon, the value of $E_{\mathrm{g}}$ is equal to $1.12 \mathrm{eV}$; however, certain modifications may be introduced to its crystal lattice, as a result of which it is possible to change the physical properties of the material, in particular the distribution of energy levels, as well as the width of the energy gap. One of the methods enabling the modification of the internal structure of silicon, which results in the change of dielectric permittivity, resistivity and the creation of additional energy levels in the silicon band model, is ion implantation, which was shown in the works [10-13]. Moreover, it is known that the change of implantation parameters, such as energy and dose, as well as temperature and time of post-implantation annealing, allow for precise control of the process of introducing the above-mentioned structural modifications of the material.

\subsection{Current Research Directions Using Ion Implantation}

The results of mathematical modeling and laboratory experiments so far clearly indicate that in order to effectively reduce the internal optical losses it is necessary to be able to precisely control the distribution of crystal lattice defects in silicon cells. Such a possibility is provided by the use of ion implantation, therefore the idea of using defects to improve the absorption of silicon cells is the subject of many scientific works. The significant influence of defects on the absorption range of real silicon structures is discussed in the work [14]. It presents the results of optoelectronic characterization of p-type silicon layers with resistivities ranging from $5 \Omega \mathrm{cm}$ to $25 \Omega \mathrm{cm}$, implanted at room temperature with sulfur, selenium, and tellurium ions with energies equal to $95 \mathrm{keV}, 176 \mathrm{keV}$, and $245 \mathrm{keV}$, respectively, and doses ranging from $3 \times 1014 \mathrm{~cm}^{-2}$ to $1016 \mathrm{~cm}^{-2}$. After implantation, the specimens were subjected to a pulsed laser melting (PLM) process. The transmission and reflection measurements showed a very high absorption coefficient in the energy range smaller than the silicon energy gap. The middle of the low-energy photon absorption band was located near the energy of $0.5 \mathrm{eV}$ for sulfur and selenium ions and $0.3 \mathrm{eV}$ for tellurium ions, while the extreme position of the lower edge of the band was determined to be within $0.05 \mathrm{eV}$. Nevertheless, it was observed that the bandwidth is not constant and increases with increasing dopant concentration. Moreover, annealing of strongly defected structures even at low temperatures of the order of $(200 \div 400){ }^{\circ} \mathrm{C}$ leads to absorption weakening.

In order to explain the nature of this phenomenon and to identify the structures responsible for the existence of absorption in the low energy range, a model was developed for the transition of the defected silicon layer from the state of strong absorption to the state of weak absorption of photons with energies lower than the value of the energy gap. The basic assumptions of the model are presented in the work [15]. After approximation of the modeled process by the Arrhenius equation, the absorption activation energies for each type of implanted ions were obtained to be $0.338 \mathrm{eV}, 0.471 \mathrm{eV}$, and $0.357 \mathrm{eV}$ for sulfur, selenium, and tellurium ions, respectively. Based on this, several potential interstitial defects that may be responsible for the occurrence of the extended absorption phenomenon were identified.

Attempts to formulate a generalized description of the results obtained empirically, led to the development of a model based on which it was shown that the introduction of selected deep defects in the charge carrier capture region can be used to improve the efficiency of silicon solar cells. The course of the defect design process on the example of a silicon solar cell is presented in [16]. In particular, defects have been identified that facilitate the transport of majority charge carriers and/or prevent the accumulation of minority carriers, which impair recombination in the charge carrier capture region. Thus, the idea of deliberately introducing defects into the structure of a solar cell enables efficient transport of charge carriers and thus reduces optical losses.

Intensive research is also carried out to improve quantum losses in silicon cells. However, the most advanced concepts are currently in the laboratory verification phase, 
and no technical solution in this area has been commercialized. Nevertheless, taking into account the current state of the art in this area, as well as the research results presented in the world literature, it can be concluded that achieving this goal will be possible through the use of ion implantation. A research direction with a very high development potential in this field is the idea of IBSC cells (Intermediate Band Solar Cells). It is one of the third generation solar cell concepts and refers mainly to silicon. The theoretical basis of IBSC cells has been known for many years, and a model of an ideal cell of this type was presented in [17]. In this model, it was shown that the ideal efficiency of IBSC cells is equal to $63.2 \%$, however, work is still ongoing to find a material that will allow for at least partial fulfillment of these assumptions.

The basic feature that distinguishes IBSC-type structures is an additional intermediate band, consisting of allowed energy states, located between the valence band and the conduction band. This configuration allows absorption of photons with energies lower than the energy gap through multiphase transport of charge carriers between valence band, intermediate band and conduction band. As a result, the ratio between the number of photons incident on the cell surface and the number of excited electrons is changed in favor of higher quantum efficiency, compared to standard silicon cells. At the same time, the photocurrent density of the cell is increased, and thus also its fill factor.

Despite the fact that from a theoretical point of view, the principle of operation of IBSC-type cells has been comprehensively described in [18], the problem of practical implementation of this concept in the form of a semiconductor material with an intermediate energy bandwidth, ensuring effective conversion of solar energy into electricity, still remains valid. Therefore, the mechanism of the formation of intermediate bands in semiconductors, as well as its utilitarian aspects, is the subject of many research papers, including a few selected current research directions based on the use of ion implantation [19-25]. One of them is an approach that includes the use of ion implantation to introduce dopants of very high concentration into the semiconductor substrate [25] or subjecting the silicon layer to implantation with metal ions of very high doses $[20,23]$.

Successive progress in the use of titanium ions for this purpose was published in a series of theoretical and experimental papers [26-28]. At first, it was confirmed that implantation of a highly resistive silicon layer $(\rho \approx 200 \Omega \mathrm{cm})$ with titanium ions with energies in the range of $(35 \div 170) \mathrm{keV}$ and doses in the range of $(1015 \div 1016) \mathrm{cm}^{-2}$ in selected cases causes a significant increase in the absorption of photons with energies below the energy gap value. Moreover, it has been shown that the strong photoconductivity is not related to the presence of crystal lattice defects, and the observed increase in the absorption coefficient and the extension of the lifetime of the photoexcited charge carriers are due to the high concentration of titanium ions [27]. As a result of further work, the formation of an intermediate energy band in a silicon layer implanted with titanium ions was confirmed at a sufficiently high dopant concentration [26]. Moreover, it was experimentally proven for the first time that recombination is inhibited when the concentration of titanium ions is high enough. The location of the center of the intermediate energy band was determined at a distance of $(0.205 \div 0.278) \mathrm{eV}$ below the conduction band, depending on the ion dose. After finding the existence of the intermediate band in the structure of the material, an attempt was made to characterize it experimentally. For this purpose, the position of deep energy levels forming the band was determined by thermal admittance spectroscopy. As a result, a clear relationship between the values of activation energy and active cross-section of charge carrier capture was observed. It was also confirmed that this relationship meets the Meyer-Neldel rule, which is characteristic of processes taking place in disordered structures, such as defective silicon, involving multiple excitation, which occurs in the case of emission and capture of charge carriers at deep energy levels [28]. The final result of the research work on the configuration of deep energy levels in silicon implanted with titanium ions is a comprehensive mathematical and physical model presented in [23], presenting in a consistent way conditions for the creation of additional energy levels with a different degree of density in the excited energy region. The model presents mechanisms 
for the formation of a continuous intermediate band, multiple discrete levels comprising a quasi-continuous band, or a single deep energy level, depending on the concentration of titanium dopants.

The presented analysis of the world literature on current research directions, confirms the effectiveness of the use of ion implantation to generate additional energy levels in the band structure of monocrystalline silicon, and the development potential in this field is so large that the conduct of further research work is justified and even necessary.

The research conducted by the authors of the article on the change of electrical parameters of silicon through the use of neon ion implantation [29-32] has led to the development of the author's method for producing and identifying additional energy levels in the band structure of semiconductors. This direction fits perfectly into the current research trend and is in line with the market trends of increasing use of ion implantation in PV cell production [33,34].

The main goal of this paper is to determine the effect of $\mathrm{Ne}^{+}$neon ion dose on the efficiency of generating additional energy levels in the band gap of p-type boron-doped silicon as a base material for photovoltaic cells. The research was aimed at determining the influence of the degree and type of the p-type silicon defect on its electrical parameters in terms of the possibility of producing intermediate energy levels in the semiconductor band gap.

\section{Materials and Methods}

Studies previously conducted by the authors' team $[13,32]$ allowed us to select the research material, which was p-type monocrystalline silicon commonly used in photovoltaics, doped with boron, with resistivity $\rho=0.4 \Omega \mathrm{cm}$. The semiconductor wafers were implanted at room temperature with $\mathrm{Ne}^{+}$neon ions with energy $E=100 \mathrm{keV}$ and three different doses of $D, 4.0 \times 10^{13} \mathrm{~cm}^{-2}, 2.2 \times 10^{14} \mathrm{~cm}^{-2}$ and $4.0 \times 10^{14} \mathrm{~cm}^{-2}$, respectively. In order to facilitate the identification of the experimental results presented in this paper, the wafers were labeled as follows:

- $\mathrm{Si}+\mathrm{B}_{1}$-neon ion implantation with a dose $D=4.0 \times 10^{13} \mathrm{~cm}^{-2}$,

- $\mathrm{Si}+\mathrm{B}_{2}$-neon ion implantation with a dose $D=2.2 \times 10^{14} \mathrm{~cm}^{-2}$,

- $\mathrm{Si}+\mathrm{B}_{3}$-neon ion implantation with a dose $D=4.0 \times 10^{14} \mathrm{~cm}^{-2}$.

Neon ions have been chosen due to the fact that they generate mainly point defects, whose deliberate introduction into the crystal lattice of silicon during the implantation process allows changing its basic electrical properties, such as energy gap width and resistivity. At the same time, it is well known that these parameters have a significant impact on the internal losses in photovoltaic cells [35].

In order to obtain data on determining the optimal dose of implanted neon ions due to the possibility of generating intermediate energy levels in the semiconductor's band gap, experimental studies were carried out. These consisted of measuring the electrical properties of suitably prepared samples, such as capacitance and conductance at varying the frequency of the measurement signal and the instantaneous operating temperature of the test sample. The results of the measurements were recorded for operating temperatures in the range of $200 \mathrm{~K}$ to $373 \mathrm{~K}$ with a step of $10 \mathrm{~K}$, after forcing in the circuit a signal of frequency in the range of $1 \mathrm{kHz}$ to $10 \mathrm{MHz}$ and a voltage of $0.5 \mathrm{~V}$.

Between each measurement cycle, in order to remove unnecessary radiation defects, the samples were heat treated by 15-min isochronous annealing at temperatures $T_{\mathrm{a}}$ of $473 \mathrm{~K}, 598 \mathrm{~K}, 673 \mathrm{~K}$, and $873 \mathrm{~K}$. Based on the results of research work [36,37], the upper limit of annealing of the tested samples was set at $873 \mathrm{~K}$. The thermal treatment of the samples at higher temperatures causes the complete disappearance of defects formed by ion implantation in the silicon structure, and thus eliminates the possibility of generating additional energy levels in the band gap.

In the course of the research work, a laboratory test stand was designed and constructed to test the electrical parameters of the samples described above. The construction of the stand was presented in detail in the work [36] and ensured repeatability of mea- 
surements due to the possibility of precise regulation and maintenance of conditions in which the tested object worked. The pictures of the research equipment, included in the laboratory stand, are shown in Figure 1.
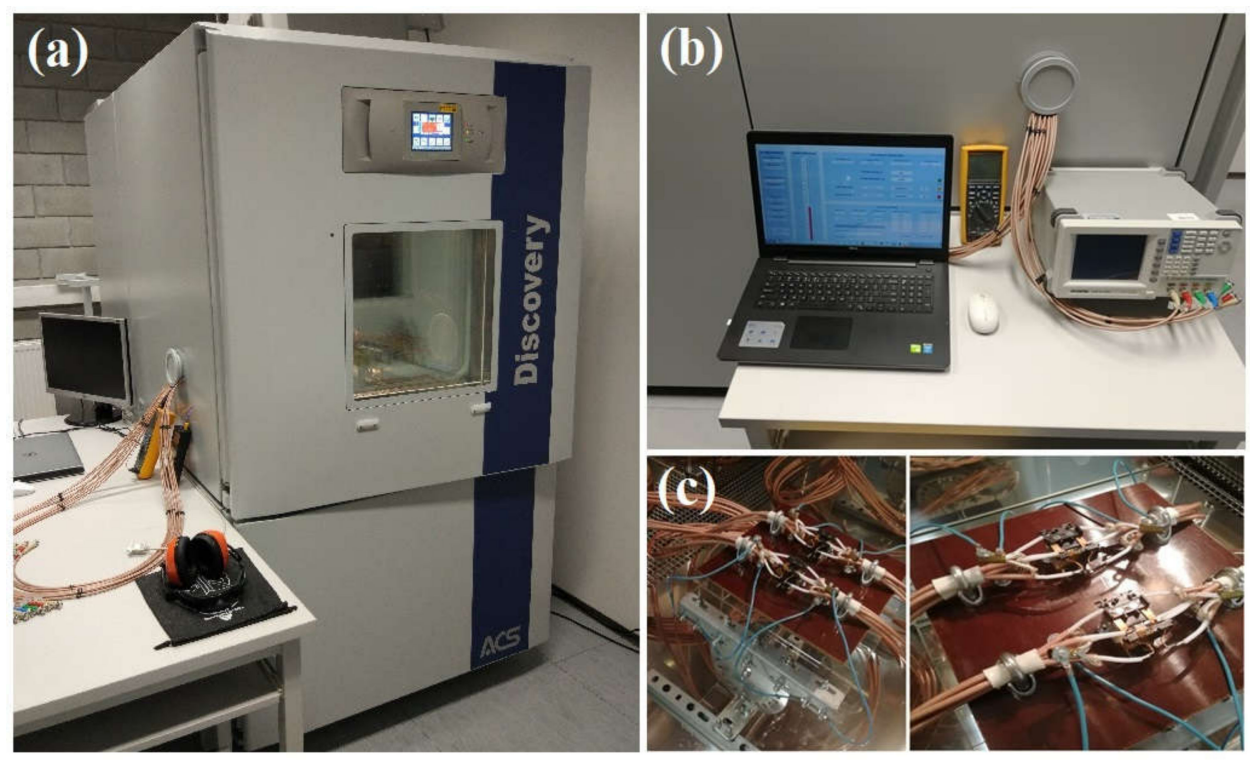

Figure 1. Laboratory stand for testing the electrical parameters of photovoltaic cells, (a)—Discovery DY600C environmental test chamber, (b) - measuring equipment (LCR meter, digital multimeters, computer software), (c)—measuring holders for placing silicon samples inside the climatic chamber.

The study was carried out using a Discovery DY600C climate chamber by the Italian Angelantoni Test Technologies company, using the proprietary PV Cells Meter computer program and the Winkratos software in the 5.00.04.00-STD-S7 version. The precision LCR-8000G Series LCR Meter by the Taiwanese GW Instek manufacturer was used to measure the capacitance and conductance values, while the sample temperature value was measured using Fluke 289 True-RMS Data Logging Multimeter by the American Fluke Corporation and Lutron TM-917 precision 0.01 degree thermometer by the American Lutron Electronics manufacturer [35,36].

The obtained measurement results allowed for the analysis of the effect of ion dose on the measured electrical parameters, i.e., capacitance and conductance, and consequently for the determination of the value of depositing additional energy levels in the band gap. For this purpose, the method of the Thermal Admittance Spectroscopy (TAS) was used which made it possible to determine the $e^{\mathrm{t}}\left(T_{\mathrm{p}}\right)$ rate determining the thermal emission. Then, on the basis of the determined temperature dependence of the $e^{t}\left(T_{\mathrm{p}}\right)$ rate, as well as the Arrhenius curves, it was possible to calculate the value of the conduction activation energy $\Delta E$, which determines the depth of the additional intermediate energy level in the silicon band gap.

The conducted research confirmed that the implantation of $\mathrm{Ne}^{+}$neon ions causes the generation of radiation defects in the silicon crystal lattice, as a base material for photovoltaic cells, and gives the possibility to produce intermediate energy levels in the band gap, which can cause the absorption of photons with energies smaller than the width of the energy gap $E_{\mathrm{g}}$.

\section{Results and Discussion}

Measurements of the temperature dependence of the electrical properties of silicon, the methodology of which was presented in the previous section, provided information on the effects of deliberate changes in the crystal lattice structure by implantation of neon ions into the silicon substrate. The research task was to verify the influence of the dose of implanted ions on the value of activation energy of selected types of radiation defects, 
which are responsible for generation of additional energy levels in the band gap of p-type silicon, doped with boron. Taking into account the fact that the defects of silicon crystal lattice, formed as a result of neon ion implantation, can be used to reduce the quantum losses in solar cells by forming silicon structures meeting the assumptions of IBSC concepts, the solution of the task specified in this way imposed the necessity of detailed analysis of the configuration of energy levels existing in silicon subjected to neon ion implantation. Thermal Admittance Spectroscopy (TAS) was used to perform this analysis using an empirical method. At the same time, it should be noted that the method used by the authors differs fundamentally from the studies described in the introduction. The idea is to generate deep energy levels by intrinsic defects caused by implantation of electrophysically inert neon ions, and not to introduce additional defects into the silicon structure in the form of dopants and impurities from active elements. The mechanism of energy absorption and electric charge transfer in semiconductors implanted with neon ions is described in detail in [37].

The TAS technique allows the determination of the thermal emission rate $e^{t}$, which is related to the temperature-induced flow of charge carriers over the potential barrier, which occurs as a result of the transfer of thermal energy to them in excess of the value of the output work. The value of the $e^{t}$ rate for deep energy levels can be determined by measuring changes in capacitance $C$ and conductance $G$ as a function of temperature and frequency. The measured changes in $C$ and $G$ are the result of thermally induced fluctuations in the values of the time constants of emission and trapped charge carriers and are dependent on the frequency of the measurement signal. The measurement methodology assumes recording the values of $C$ and $G$ for specific frequencies of the measurement signal, under varying temperature conditions. Each deep energy level, occurring in the energy gap region of the semiconductor under study, exhibits a maximum of the conductance $G_{\mathrm{m}}$ at temperature $T_{\mathrm{m}}$ and an inflection point of the capacitance $C_{\mathrm{i}}$ at temperature $T_{\mathrm{i}}$, so that it is possible to determine the value of the thermal emission rate $e^{t}$ using well-known formulas [38]:

$$
\begin{aligned}
& e^{\mathrm{t}}\left(T_{m}\right)=\frac{\omega}{1.98}, \\
& e^{t}\left(T_{i}\right)=\frac{\omega}{1.825},
\end{aligned}
$$

where: $e^{\mathrm{t}}\left(T_{\mathrm{m}}\right)$-thermal emission rate at temperature $T_{\mathrm{m}}, e^{\mathrm{t}}\left(T_{\mathrm{i}}\right)$-thermal emission rate at temperature $T_{\mathrm{i}}, \omega$-pulsation.

Therefore, performing measurements at different frequencies allows the temperature dependence of the $e^{t}$ rate, from which the activation energy $\Delta E$ and the active cross-section of charge carrier capture by the trap $\sigma_{\mathrm{T}}$, which is a measure of the probability of free carrier capture by deep defect centers, can be determined.

The application of the Thermal Admittance Spectroscopy method allows the characterization of deep energy levels in those materials in which the dopant concentration is lower than the concentration determining the Mott transition limit. The reason for this situation is that in materials for which the dopant concentration exceeds the Mott limit, the Fermi level is located near the defect band. This, in turn, makes the samples resistive in nature, and thus there is no modulation of the depleted layer depth depending on the polarization voltage. In contrast, materials with dopant concentrations below the Mott limit show a strong dependence of the capacitance value on the polarization voltage, indicating the presence of depleted layer modulation [26].

For materials with dopant concentrations above the Mott transition limit, the temperature dependence of $C$ and $G$ does not show the existence of deep levels in the manner typical for dopant concentrations less than the Mott limit, i.e., through local maxima and inflection points. The lack of signs of the presence of deep energy levels in the admittance spectra is consistent with the assumptions of the intermediate energy band theory, which predicts that deep energy levels cease to be centers of recombination when an intermediate band is formed. 
In the remainder of this paper, the analysis is limited to the results of conductance $G$ measurements of the tested samples.

In the first phase of the analysis of the obtained results, the data on the temperature dependence of conductance for each implantation dose and selected frequencies were collected and presented in graphical form in Figure 2a,b. The analysis of the presented dependencies indicates that in the case of samples subjected to ion implantation with each of the applied doses changes were caused in conductance, which are associated with the phenomena of charging and discharging of deep energy levels, taking into account the frequency of the measurement signal. The occurrence of deep energy levels in the energy gap region of the investigated semiconductor samples is confirmed by the occurrence of inflection points and local maxima in the courses of conductance dependence as a function of temperature. Taking this into account, it can be noted that in the case of all investigated samples such phenomena do not occur. Moreover, it can be observed that the amplitudes of the local maxima of conductance measured for individual samples reach different values, which indicates different concentration of deep recombination centers, the highest in the case of the sample implanted with a dose of $D=2.2 \times 10^{14} \mathrm{~cm}^{-2}$.

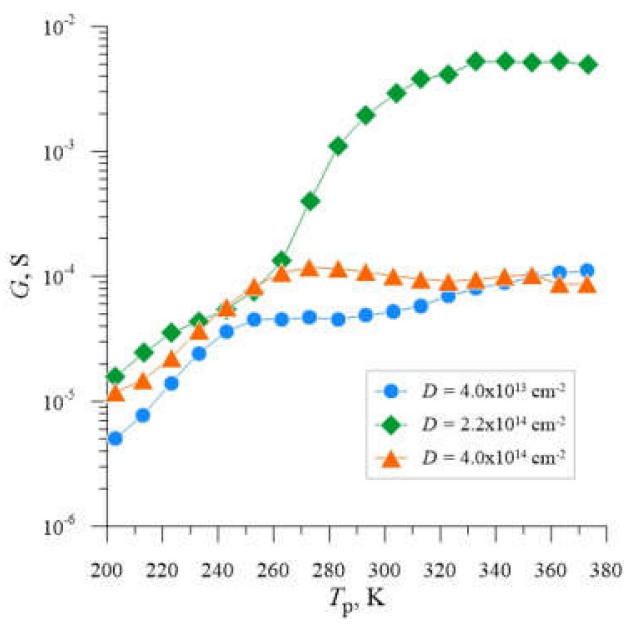

(a)

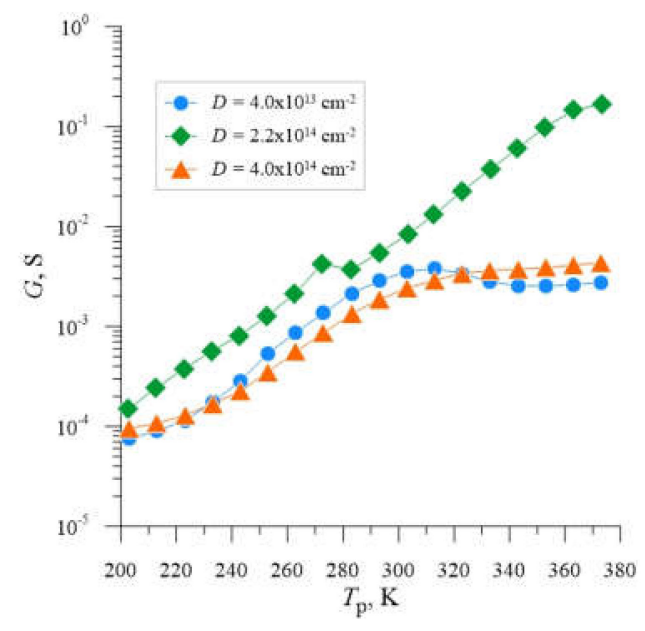

(b)

Figure 2. Dependencies $G=\mathrm{f}\left(T_{\mathrm{p}}\right)$ for silicon with resistivity $\rho=0.4 \Omega \mathrm{cm}$, boron-doped, implanted with $\mathrm{Ne}^{+}$neon ions with energy $E=100 \mathrm{keV}$, annealed at $T_{\mathrm{a}}=598 \mathrm{~K}$, determined for the frequency $f$ of $10 \mathrm{kHz}$ (a) and $1 \mathrm{MHz}$, respectively, (b) and three different doses of ions $D=4.0 \times 10^{13} \mathrm{~cm}^{-2}$; $2.2 \times 10^{14} \mathrm{~cm}^{-2} ; 4.0 \times 10^{14} \mathrm{~cm}^{-2}$.

The choice of the post-implantation annealing temperature $T_{\mathrm{a}}=598 \mathrm{~K}$ as the optimum temperature due to the selection of Si-B3-type radiation defects with the highest concentration, which introduce additional energy levels in the semiconductor's band gap, follows from the analysis of the literature [39] and previous studies [40]. In order to confirm this fact, the $G=f\left(T_{p}\right)$ dependencies were developed for individual samples and four different annealing temperatures $T_{a}$ (Figures $3 a, 4 a$ and $5 a$ ), from which it can be seen that for each of the implantation doses used, local maxima and characteristic inflection of the $G=f\left(T_{p}\right)$ curve occur for temperature $T_{\mathrm{a}}=598 \mathrm{~K}$. Figures $3 \mathrm{~b}, 4 \mathrm{~b}$ and $5 \mathrm{~b}$ show analogous $G=\mathrm{f}\left(T_{\mathrm{p}}\right)$ relationships for individual samples, for the previously selected post-implantation annealing temperature $T_{\mathrm{a}}=598 \mathrm{~K}$ and different frequencies $f$. In this case, we also observe local conductance maxima whose location shifts towards higher sample temperatures $T_{\mathrm{p}}$ with increasing frequency. 


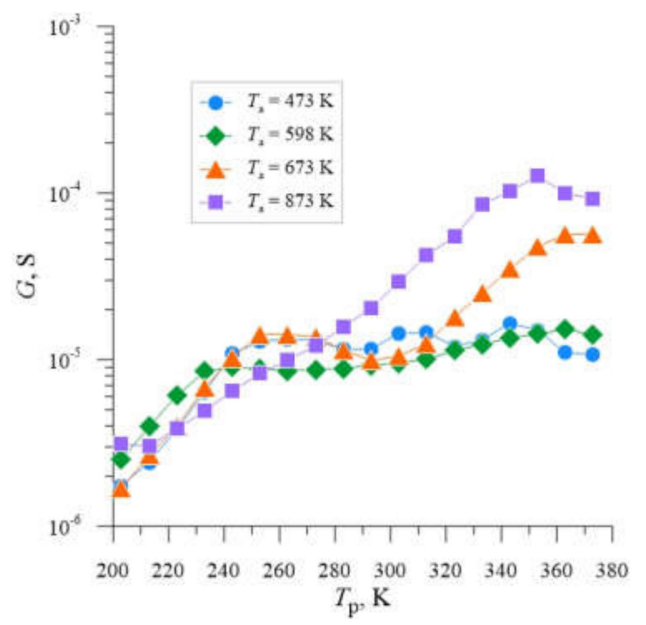

(a)

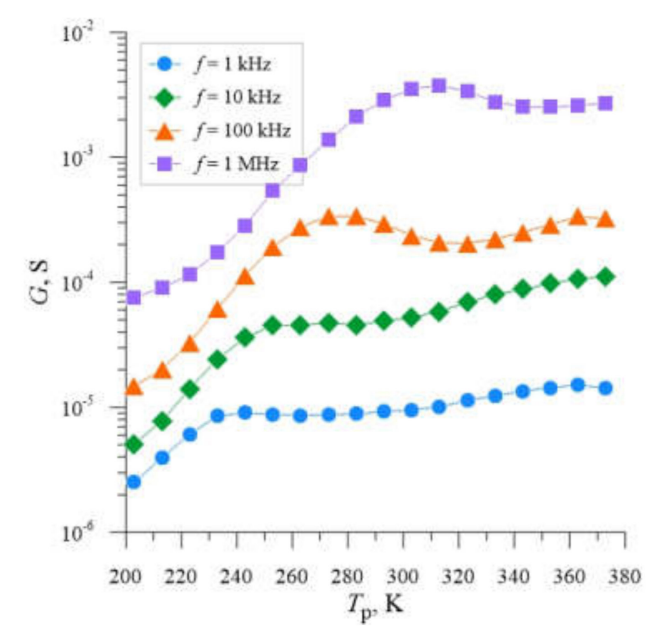

(b)

Figure 3. Dependencies $G=\mathrm{f}\left(T_{\mathrm{p}}\right)$ for silicon with resistivity $\rho=0.4 \Omega \mathrm{cm}$, boron-doped, implanted with $\mathrm{Ne}^{+}$neon ions with energy $E=100 \mathrm{keV}$ and dose $D=4.0 \times 10^{13} \mathrm{~cm}^{-2}$, determined for the frequency $f=1 \mathrm{kHz}$ and four different annealing temperatures $T_{\mathrm{a}}$ (a) and annealing temperature $T_{\mathrm{a}}=598 \mathrm{~K}$ and four different measurement frequencies $f(\mathbf{b})$.

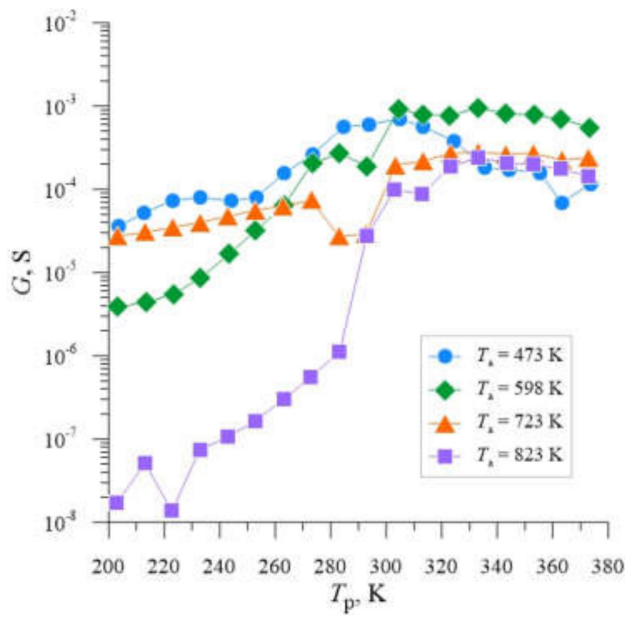

(a)

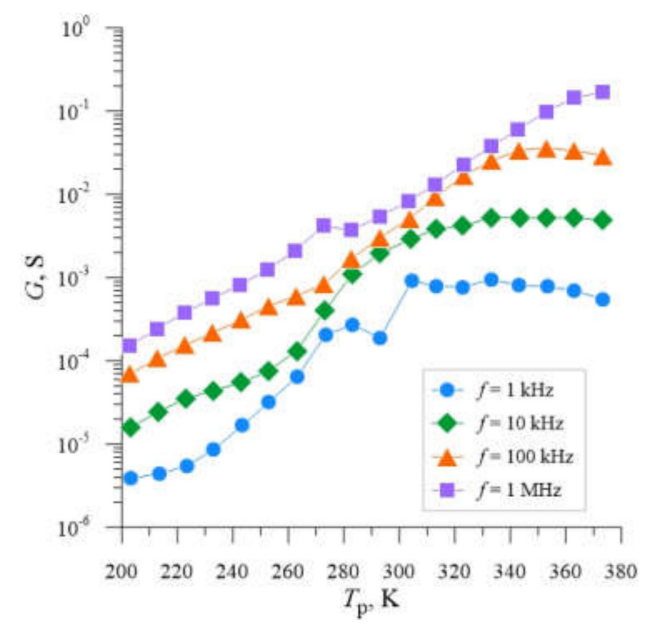

(b)

Figure 4. Dependencies $G=\mathrm{f}\left(T_{\mathrm{p}}\right)$ for silicon with resistivity $\rho=0.4 \Omega \mathrm{cm}$, boron-doped, implanted with $\mathrm{Ne}^{+}$neon ions with energy $E=100 \mathrm{keV}$ and dose $D=2.2 \times 10^{14} \mathrm{~cm}^{-2}$, determined for the frequency $f=1 \mathrm{kHz}$ and four different annealing temperatures $T_{\mathrm{a}}$ (a) and annealing temperature $T_{\mathrm{a}}=598 \mathrm{~K}$ and four different measurement frequencies $f(\mathbf{b})$.

The second phase of the study was to determine the value of activation energy of deep levels found in the tested samples. For this part of the analysis, in accordance with the justification presented above, the samples annealed at $T_{\mathrm{a}}=598 \mathrm{~K}$ were chosen, for which the doses of neon ions were $4.0 \times 10^{13} \mathrm{~cm}^{-2}, 2.2 \times 10^{14} \mathrm{~cm}^{-2}$ and $4.0 \times 10^{14} \mathrm{~cm}^{-2}$. The calculations were performed for the voltage of measuring signal $U_{\mathrm{p}}=0.5 \mathrm{~V}$. In all cases, the analysis procedure was analogous. It included the determination of the dependence of the measured conductance $G$, related to the value of the pulsation $\omega$ as a function of the measurement temperature $T_{\mathrm{p}}$ for different values of the frequency of the measurement signal $f$, as shown in Figure 6. 


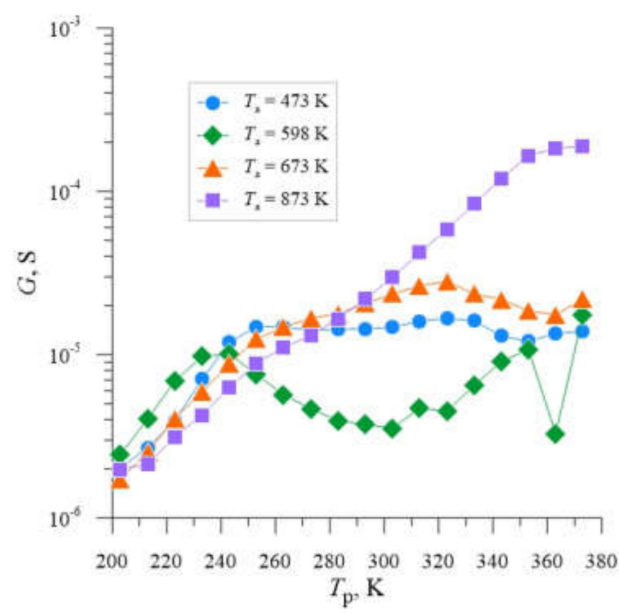

(a)

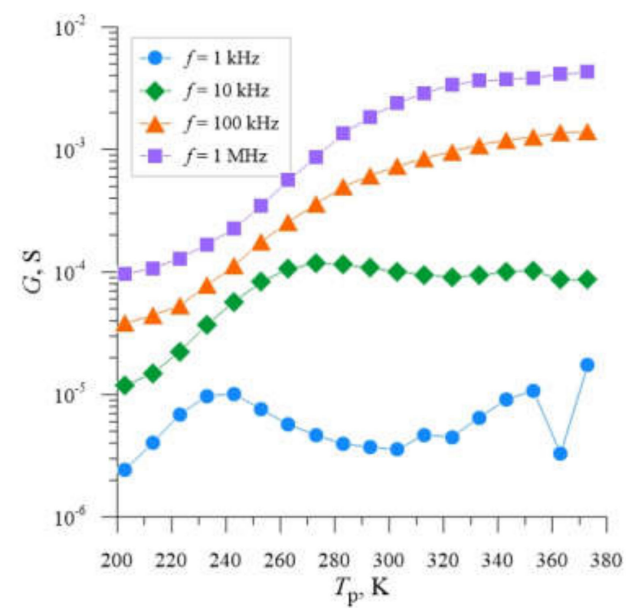

(b)

Figure 5. Dependencies $G=\mathrm{f}\left(T_{\mathrm{p}}\right)$ for silicon with resistivity $\rho=0.4 \Omega \mathrm{cm}$, boron-doped, implanted with $\mathrm{Ne}^{+}$neon ions with energy $E=100 \mathrm{keV}$ and dose $D=4.0 \times 10^{14} \mathrm{~cm}^{-2}$, determined for the frequency $f=1 \mathrm{kHz}$ and four different annealing temperatures $T_{\mathrm{a}}$ (a) and annealing temperature $T_{\mathrm{a}}=598 \mathrm{~K}$ and four different measurement frequencies $f(\mathbf{b})$.

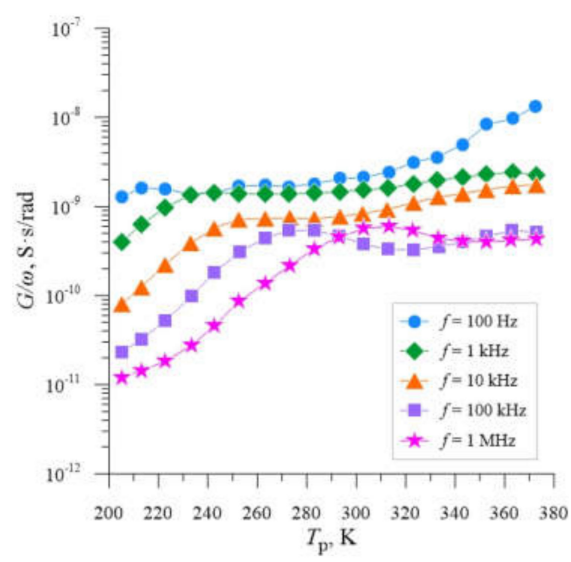

(a)

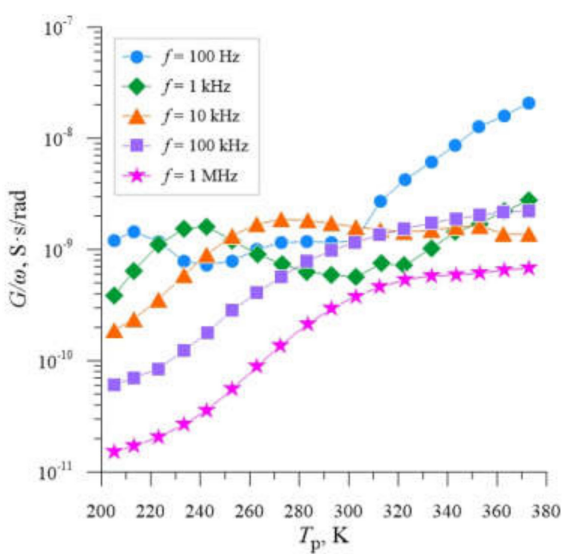

(c)

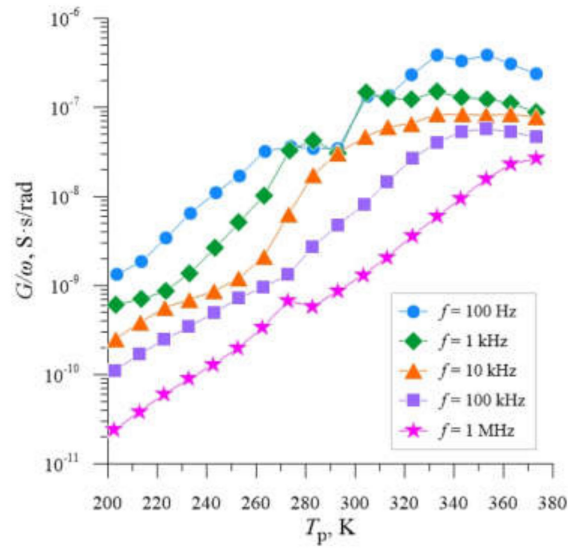

(b)

Figure 6. Dependencies $G / \omega=\mathrm{f}\left(T_{\mathrm{p}}\right)$ for silicon with resistivity $\rho=0.4 \Omega \mathrm{cm}$, boron-doped, implanted with $\mathrm{Ne}^{+}$neon ions with energy $E=100 \mathrm{keV}$ and doses of $D=4.0 \times 10^{13} \mathrm{~cm}^{-2}(\mathbf{a}), D=2.2 \times 10^{14} \mathrm{~cm}^{-2}(\mathbf{b})$, $D=4.0 \times 10^{14} \mathrm{~cm}^{-2}$, respectively, (c) determined for different $f$ and the annealing temperature $T_{\mathrm{a}}=598 \mathrm{~K}$. 
As can be seen, for each plotted relation, the location of the local maxima is characteristic of a certain frequency $f$ and thus of the corresponding pulsation, and changes with increasing the operating temperature of the sample $T_{p}$. According to the explanation suggested in the work [41], the local maximum of the conductance $G_{\max }$, which corresponds to the value of $G_{\max } / \omega$, determined for the temperature value $T_{\mathrm{p}(\max )}$, as shown in Figure 7 , is related to the thermal emission rate of the deep energy level $e^{\mathrm{t}}\left(T_{\mathrm{p}(\max )}\right)$. By calculating the values of the pulsation $\omega$, for each frequency, we can calculate the values of $e^{t}\left(T_{p(\max )}\right)$, according to Equation (1).

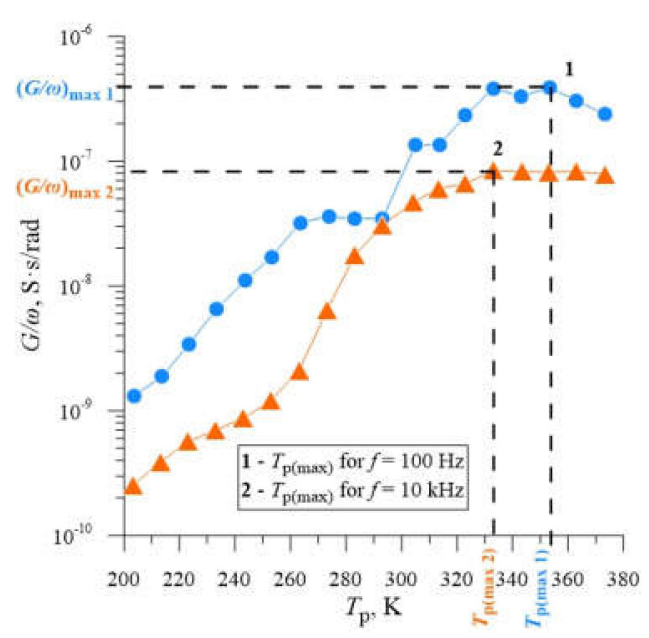

Figure 7. The method of determining the value of $G_{\max } / \omega$ and $T_{\mathrm{p}(\max )}$ on the example of the dependence $G / \omega=\mathrm{f}\left(T_{\mathrm{p}}\right)$ for silicon with resistivity $\rho=0.4 \Omega \mathrm{cm}$, doped with boron, implanted with neon ions $\mathrm{Ne}^{+}$with energy $E=100 \mathrm{keV}$ and dose $D=2.2 \times 10^{14} \mathrm{~cm}^{-2}$, plotted for the measurement frequencies $f=100 \mathrm{~Hz}$ and $10 \mathrm{kHz}$ and the annealing temperature $T_{\mathrm{a}}=598 \mathrm{~K}$.

On the other hand, it is known that the thermal emission rate of the deep energy level $e^{t}(T)$ can be expressed as follows [38]:

$$
e^{t}(T)=\sigma_{T} v_{\text {th }} N_{c} \exp \left(-\frac{\Delta E}{k T}\right),
$$

where: $\sigma_{\mathrm{T}}$-active carrier capture cross section, $v_{\mathrm{th}}$-thermal rate of charge carriers, $N_{\mathrm{C}}-$ concentration of defects in conduction band, $\Delta E$-activation energy, $T$-temperature, $k$-the Boltzmann's constant.

Since it is known that the value of $v_{\text {th }}$ is proportional to $T^{1 / 2}$, while the value of $N_{C}$ is proportional to $T^{3 / 2}$, Equation (3) can be transformed to the following form:

$$
e^{t}(T) / T^{2}=\gamma \sigma_{T} \exp \left(-\frac{\Delta E}{k T}\right),
$$

where $\gamma$ includes the value of the coefficients $v_{\text {th }}$ and $N_{C}$ and does not depend on temperature

The relation (4) is in the form of Arrhenius equation, so it is possible to determine the activation energy of deep energy levels by approximation of experimental data with a linear function. The results of such approximation for an annealing temperature of $598 \mathrm{~K}$ are presented in Figure 8.

On the basis of the analysis carried out, the existence of intermediate energy levels in the structure of the studied samples in the semiconductor band gap, with activation energies dependent on the dose of implanted neon ions, amounting to respectively:

- $\quad$ sample $\mathrm{Si}+\mathrm{B}_{1}-\Delta E_{1}=0.3412 \mathrm{eV}$ for $D=4.0 \times 10^{13} \mathrm{~cm}^{-2}$ (Figure 8a),

- $\quad$ sample $\mathrm{Si}+\mathrm{B}_{2}-\Delta E_{2}=0.4632 \mathrm{eV}$ for $D=2.2 \times 10^{14} \mathrm{~cm}^{-2}$ (Figure 8b),

- $\quad$ sample $\mathrm{Si}+\mathrm{B}_{3}-\Delta E_{3}=0.3208 \mathrm{eV}$ dla $D=4.0 \times 10^{14} \mathrm{~cm}^{-2}$ (Figure 8c). 


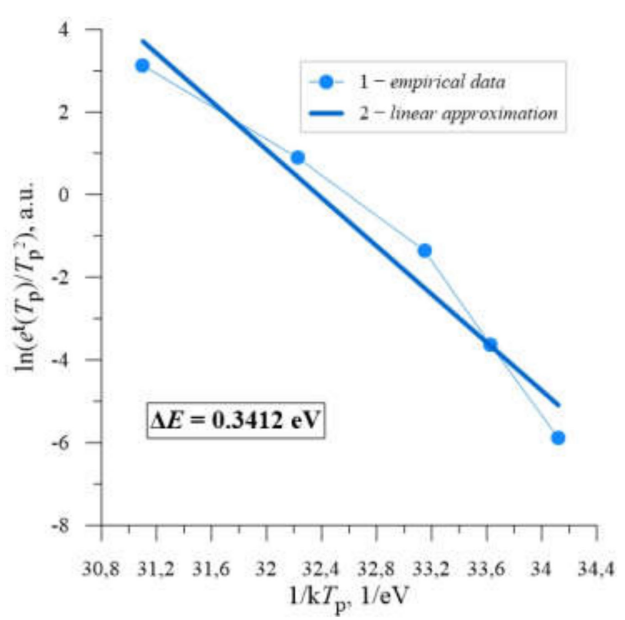

(a)

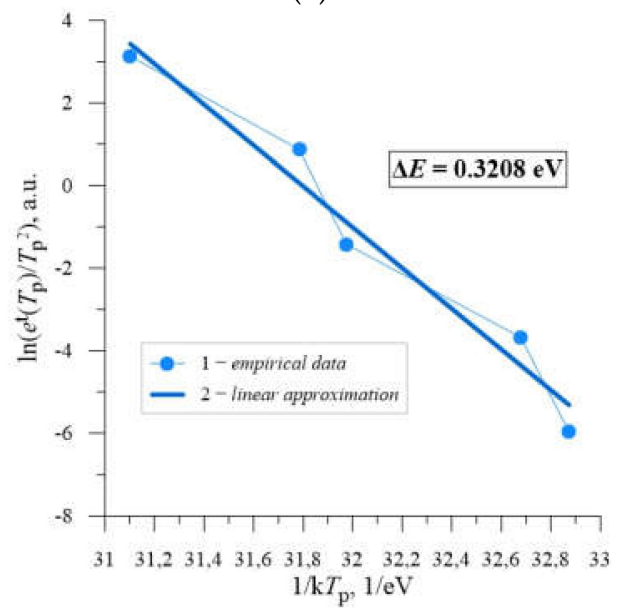

(c)

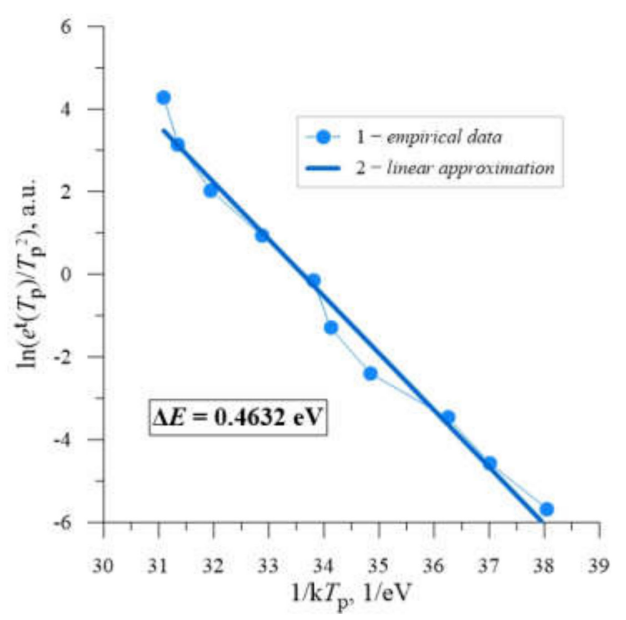

(b)

Figure 8. The Arrhenius plots of the function $\ln \left(e^{t}\left(T_{\mathrm{p}}\right) / T_{\mathrm{p}}{ }^{2}\right)=\mathrm{f}\left(1 / k T_{\mathrm{p}}\right)$ for silicon with $\rho=0.4 \Omega \mathrm{cm}$, doped with boron, implanted with $\mathrm{Ne}^{+}$neon ions with energy $E=100 \mathrm{keV}$ and doses $D=4.0 \times 10^{14} \mathrm{~cm}^{-2}(\mathbf{a}), D=2.2 \times 10^{14} \mathrm{~cm}^{-2}(\mathbf{b})$ and $D=4.0 \times 10^{14} \mathrm{~cm}^{-2}$ (c), annealed at $T_{\mathrm{a}}=598 \mathrm{~K}: 1$-empirical data, 2-linear approximation.

\section{Conclusions}

The analysis performed was focused on the identification of intermediate energy levels in the band gap of boron-doped silicon with resistivity $\rho=0.4 \Omega \mathrm{cm}$, resulting from implantation with $\mathrm{Ne}^{+}$ions of different doses. For each of the three applied ion doses, which are $4.0 \times 10^{13} \mathrm{~cm}^{-2}, 2.2 \times 10^{14} \mathrm{~cm}^{-2}$ and $4.0 \times 10^{14} \mathrm{~cm}^{-2}$, the existence of deep energy levels with activation energies of $0.34 \mathrm{eV}, 0.46 \mathrm{eV}$ and $0.32 \mathrm{eV}$, respectively, was observed.

Thus, the possibility of using the implantation of neon ions to defect silicon structures in such a way that additional energy levels are generated in the band gap of the semiconductor was confirmed. The results of the conducted research should be considered in terms of potential use in the manufacturing process, by the method of ion implantation, of monocrystalline silicon photovoltaic cells. Especially noteworthy are the results obtained with the implantation of neon ions at a dose of $2.2 \times 10^{14} \mathrm{~cm}^{-2}$, which allowed the generation of an additional energy level with an activation energy of $\Delta E=0.46 \mathrm{eV}$, i.e., near the center of the silicon band gap $\left(E_{\mathrm{g}}=1.12 \mathrm{eV}\right)$. This will provide a multi-step mechanism for the absorption of photons with energies below the width of the band gap.

The practical implementation of the concept of energy-efficient silicon photovoltaic cells with intermediate energy levels in the semiconductor band gap, generated by means of 
neon ion implantation, requires further research. They must be focused on the development of a technology for manufacturing complete silicon cells, taking into account the additional process of implantation of neon ions and the search for optimal implantation parameters, i.e., energy and ion dose, adapted to the properties of the substrate material, including primarily the type of dopant and resistivity.

Author Contributions: P.W. proposed to study the topic of application of neon ion implantation to generate intermediate energy levels in the band gap of boron-doped silicon as a material for photovoltaic cells with improved efficiency. P.W. and J.P. did the calculations and wrote the paper. P.W. and J.P. revised the results and contributed to the discussions. All authors have read and agreed to the published version of the manuscript.

Funding: This research was founded by Lublin University of Technology, grant number FD-20/EE-2/708.

Institutional Review Board Statement: Not applicable.

Informed Consent Statement: Not applicable.

Data Availability Statement: Data sharing is not applicable for this article.

Acknowledgments: This work was supported by Ministry of Science and Higher Education program called Innovation Incubator 4.0. The funds come from the non-competitive project "Support for the management of scientific research and commercialization of R\&D results in research units and enterprises", implemented under the Intelligent Development Operational Program 2014-2020 (grant \# POIR.04.04.00-00-0004/15).

Conflicts of Interest: The authors declare no conflict of interest.

\section{References}

1. Jäger-Waldau, A. Snapshot of Photovoltaics-February 2020. Energies 2020, 13, 930. [CrossRef]

2. Taylor, N.; Jäger-Waldau, A. Photovoltaics Technology Development Report 2020; Publications Office of the European Union: Luxembourg, 2020; pp. 3-14. [CrossRef]

3. He, Y.; Pang, Y.; Li, X.; Zhang, M. Dynamic subsidy model of photovoltaic distributed generation in China. Renew. Energy 2018, 118, 555-564. [CrossRef]

4. De Rose, A.; Buna, M.; Strazza, C.; Olivieri, N.; Stevens, T.; Peeters, L.; Tawil-Jamault, D. Technology Readiness Level: Guidance Principles for Renewable Energy Technologies; European Commission: Petten, The Netherlands, 2017; pp. 17-27. [CrossRef]

5. Fatih, B. World Energy Outlook 2019; International Energy Agency Publication: Paris, France, 2019; pp. 299-328. Available online: https: / /www.iea.org/reports/world-energy-outlook-2019 (accessed on 12 November 2021).

6. Gielen, D.; International Renewable Energy Agency (IRENA). Global Energy Transformation: A Roadmap to 2050, 2019 ed.; International Renewable Energy Agency Publication: Abu Dhabi, United Arab Emirates, 2019; pp. 15-35. Available online: https: / / www.irena.org/publications / 2019/Apr/Global-energy-transformation-A-roadmap-to-2050-2019Edition (accessed on 12 November 2021).

7. Chowdhury, S.; Kumar, M.; Dutta, S.; Park, J.; Kim, J.; Kim, S.; Ju, M.; Kim, Y.; Cho, Y.; Cho, E.-C.; et al. High-efficiency Crystalline Silicon Solar Cells: A Review. New Renew. Energy 2019, 15, 36-45. [CrossRef]

8. Ho, W.-J.; You, B.-J.; Liu, J.-J.; Bai, W.-B.; Syu, H.-J.; Lin, C.-F. Photovoltaic Performance Enhancement of Silicon Solar Cells Based on Combined Ratios of Three Species of Europium-Doped Phosphors. Materials 2018, 11, 845. [CrossRef]

9. Lee, Y.; Park, C.; Balaji, N.; Lee, Y.J.; Dao, V.A. High-efficiency silicon solar cells: A review. Isr. J. Chem. 2015, 55, 1050-1063. [CrossRef]

10. Billewicz, P.; Węgierek, P.; Grudniewski, T.; Turek, M. Application of ion implantation for intermediate energy levels formation in the silicon-based structures dedicated for photovoltaic purposes. Acta Phys. Pol. A 2017, 132, 274-277. [CrossRef]

11. Billewicz, P.; Wegierek, P. Research on distribution of energy levels in ion implanted monocrystalline silicon in the aspect of photovoltaic applications. In Proceedings of the 2017 International Conference on Electromagnetic Devices and Processes in Environment Protection with Seminar Applications of Superconductors, (ELMECO \& AoS Conference), Nałęczów, Poland, 3-6 December 2017. [CrossRef]

12. Wegierek, P.; Billewicz, P. Changes in the Activation Energy of Radiation Defects in Strongly Defected Silicon Depending on the Type and Concentration of Dopant. Acta Phys. Pol. A 2014, 125, 1392-1395. [CrossRef]

13. Kowalski, M.; Partyka, J.; Wegierek, P.; Żukowski, P.; Komarov, F.F.; Jurchenko, A.V.; Freik, D. Frequency-dependent annealing characteristics of the implant-isolated GaAs layers. Vacuum 2005, 78, 311-317. [CrossRef]

14. Umezu, I.; Warrender, J.M.; Charnvanichborikarn, S.; Kohno, A.; Williams, J.; Tabbal, M.; Papazoglou, D.; Zhang, X.-C.; Aziz, M.J. Emergence of very broad infrared absorption band by hyperdoping of silicon with chalcogens. J. Appl. Phys. 2013, 113, 213501. [CrossRef] 
15. Wang, K.F.; Shao, H.; Liu, K.; Qu, S.; Wang, Y.; Wang, Z. Possible atomic structures responsible for the sub-bandgap absorption of chalcogen-hyperdoped silicon. Appl. Phys. Lett. 2015, 107, 112106. [CrossRef]

16. Liu, Y.; Stradins, P.; Deng, H.; Luo, J.; Wei, S.H. Suppress carrier recombination by introducing defects: The case of Si solar cell. Appl. Phys. Lett. 2016, 108, 22101. [CrossRef]

17. Luque, A.; Martí, A. Increasing the efficiency of ideal solar cells by photon induced transitions at intermediate levels. Phys. Rev. Lett. 1997, 78, 5014-5017. [CrossRef]

18. Okada, Y.; Ekins-Daukes, N.J.; Kita, T.; Tamaki, R.; Yoshida, M.; Pusch, A.; Hess, O.; Phillips, C.C.; Farrell, D.J.; Ahsan, N.; et al. Intermediate band solar cells: Recent progress and future directions. Appl. Phys. Rev. 2015, 2, 21302. [CrossRef]

19. Malerba, C.; Ricardo, C.L.A.; D’Incau, M.; Biccari, F.; Scardi, P.; Mittiga, A. Nitrogen doped Cu2O: A possible material for intermediate band solar cells? Sol. Energy Mater. Sol. Cells 2012, 105, 192-195. [CrossRef]

20. López, A.B.C.; Vega, A.M.; López, A.L. (Eds.) Next Generation of Photovoltaics: New Concepts; Springer: Berlin/Heidelberg, Germany, 2012; pp. 17-38. [CrossRef]

21. Kuang, Y.J.; Yu, K.M.; Kudrawiec, R.; Luce, A.V.; Ting, M.; Walukiewicz, W.; Tu, C.W. GaNAsP: An intermediate band semiconductor grown by gas-source molecular beam epitaxy. Appl. Phys. Lett. 2013, 102, 112105. [CrossRef]

22. Lam, P.; Wu, J.; Tang, M.; Jiang, Q.; Hatch, S.; Beanland, R.; Wilson, J.; Allison, R.; Liu, H. Submonolayer InGaAs/GaAs quantum dot solar cells. Sol. Energy Mater. Sol. Cells 2014, 126, 83-87. [CrossRef]

23. Pérez, E.; Duenas, S.; Castán, H.; García, H.; Bailón, L.; Montero, D.; García-Hernansanz, R.; Hemme, E.G.; Olea, J.; González-Díaz, G.; et al. A detailed analysis of the energy levels configuration existing in the band gap of supersaturated silicon with titanium for photovoltaic applications. J. Appl. Phys. 2015, 118, 245704. [CrossRef]

24. Shan, W.; Walukiewicz, W.; Ager, J.W., III; Haller, E.E.; Geisz, J.F.; Friedman, D.J.; Olson, J.M.; Kurtz, S.R. Band anticrossing in GaInNAs alloys. Phys. Rev. Lett. 1999, 82, 1221-1224. [CrossRef]

25. Tanaka, T.; Miyabara, M.; Nagao, Y.; Saito, K.; Guo, Q.; Nishio, M.; Yu, K.M.; Walukiewicz, W. Photocurrent induced by two-photon excitation in ZnTeO intermediate band solar cells. Appl. Phys. Lett. 2013, 102, 52111. [CrossRef]

26. Castán, H.; Pérez, E.; García, H.; Dueñas, S.; Bailón, L.; Olea, J.; Pastor, D.P.; Hemme, E.G.; Irigoyen, M.; González-Díaz, G. Experimental verification of intermediate band formation on titanium-implanted silicon. J. Appl. Phys. 2013, 113, 24104. [CrossRef]

27. Olea, J.; Pastor, D.; Del Prado, Á.; García-Hemme, E.; García-Hernansanz, R.; Mártil, I.; González-Díaz, G. Ruling out the impact of defects on the below band gap photoconductivity of Ti supersaturated Si. J. Appl. Phys. 2013, 114, 53110. [CrossRef]

28. Pérez, E.; Castán, H.; García, H.; Dueñas, S.; Bailón, L.; Montero, D.; García-Hernansanz, R.; Hemme, E.G.; Olea, J.; González-Díaz, G. Energy levels distribution in supersaturated silicon with titanium for photovoltaic applications. Appl. Phys. Lett. 2015, 106, 22105. [CrossRef]

29. Wegierek, P.; Pietraszek, J. Application of poly-energy implantation with H+ ions for additional energy levels formation in GaAs dedicated to photovoltaic cells. Arch. Electr. Eng. 2019, 68, 925-931. [CrossRef]

30. Węgierek, P.; Pietraszek, J. Analysis of electricity generation efficiency in photovoltaic building systems made of HIT-IBC cells for multi-family residential buildings. Open Phys. 2019, 17, 307-312. [CrossRef]

31. Wegierek, P.; Billewicz, P. Jump Mechanism of Electric Conduction in n-Type Silicon Implanted with Ne++ Neon Ions. Acta Phys. Pol. A 2011, 120, 122-124. [CrossRef]

32. Węgierek, P.; Pastuszak, J.; Dziadosz, K.; Turek, M. Influence of Substrate Type and Dose of Implanted Ions on the Electrical Parameters of Silicon in Terms of Improving the Efficiency of Photovoltaic Cells. Energies 2020, 13, 6708. [CrossRef]

33. Park, C.; Shim, G.; Balaji, N.; Park, J.; Yi, J. Correlation between Boron-Silicon Bonding Coordination, Oxygen Complexes and Electrical Properties for n-Type c-Si Solar Cell Applications. Energies 2020, 13, 3057. [CrossRef]

34. Musztyfaga-Staszuk, M.; Janicki, D.; Panek, P. Correlation of Different Electrical Parameters of Solar Cells with Silver Front Electrodes. Materials 2019, 12, 366. [CrossRef]

35. Wegierek, P.; Billewicz, P. Research on Mechanisms of Electric Conduction in the p-Type Silicon Implanted with Ne+ Ions. Acta Phys. Pol. A. 2013, 123, 948-951. [CrossRef]

36. Billewicz, P.; Wegierek, P. Laboratory Stand for Examining the Influence of Environmental Conditions on Electrical Parameters of Photovoltaic Cells. Przeglad Elektrotech. 2016, 92, 176-179. [CrossRef]

37. Partyka, J.; Żukowski, P.W.; Wegierek, P.; Rodzik, A.; Sidorenko, Y.V.; Shostak, Y.A. Temperature dependence of the width of the deep-level band in silicon with a high concentration of defects. Semiconductors 2002, 36, 1326-1331. [CrossRef]

38. Schroder, D.K. Semiconductor Material and Device Characterization; John Wiley \& Sons: Hoboken, NJ, USA, 2006; pp. 251-288. [CrossRef]

39. Claeys, C.; Simoen, E. Radiation Effects in Advanced Semiconductor Materials and Devices; Springer Science \& Business Media: Berlin, Germany, 2002; Volume 57, pp. 109-144. [CrossRef]

40. Żukowski, P.; Partyka, J.; Weegierek, P. Effect of ion implantation and annealing on the dielectric properties of silicon. Phys. Status Solidi A 1997, 159, 509-515. [CrossRef]

41. Barbolla, J.; Duenas, S.; Bailon, L. Admittance spectroscopy in junctions. Solid-State Electron. 1992, 35, 285-297. [CrossRef] 